\title{
High-Hydrophilic and Antifouling Poly (Vinylidene Fluoride) Composite Membranes via in Situ Mosaic- Assembled Nanocrystalline Cellulose and g-C3N4
}

Hongbin Li

Qiqihar University

chao liu ( $\square$ Iwcp1981@163.com)

Shenzhen University https://orcid.org/0000-0001-6582-405X

Yongqiang Guo

Jiangsu Hengrui Medicine Co Ltd

Shuzhen Gao

Qiqihar University

\section{Research Article}

Keywords: poly (vinylidene fluoride) (PVDF), composite membranes, pineapple leaf nanocrystalline cellulose, g-C3N4

Posted Date: December 9th, 2021

DOI: https://doi.org/10.21203/rs.3.rs-1109115/v1

License: (c) (i) This work is licensed under a Creative Commons Attribution 4.0 International License. Read Full License 


\title{
High-hydrophilic and antifouling poly (vinylidene fluoride) composite membranes via in situ mosaic-assembled nanocrystalline cellulose and $\mathrm{g}-\mathrm{C}_{3} \mathrm{~N}_{4}$
}

\author{
Hongbin $\mathrm{Li}^{\mathrm{a}}$, Chao Liu ${ }^{\mathrm{b}, *}$, Yongqiang Guo ${ }^{\mathrm{c}}$, Shuzhen Gao ${ }^{\mathrm{a}}$ \\ a College of Light Industry and Textile, Qiqihar University, Qiqihar 161006, PR \\ China \\ b Water Science and Environmental Engineering Research Center, College of \\ Chemical and Environmental Engineering, Shenzhen University, Shenzhen 518060, \\ PR China \\ c Jiangsu Hengrui Medicine Co.,Ltd. Lianyungang 222000 ,PR China
}

Abstract:

Developing an antifouling and stable separation poly (vinylidene fluoride) (PVDF) membrane for water treatment is of great significance but challenging due to the limitations of its low surface properties and strong hydrophobicity. In this study, a novel multi-block composite ultrafiltration membrane was developed using the mosaic-assembled doping of pineapple leaf nanocrystalline cellulose and $\mathrm{g}-\mathrm{C}_{3} \mathrm{~N}_{4}$. The effects of adding different components on the PVDF composite membrane properties have been analyzed. The surface chemical composition, surface morphology, crystallinity and thermal stability of the composite membranes were characterized by Fourier transform infrared spectroscopy (FTIR), scanning electron microscope (SEM), X-ray diffraction (XRD) and thermogravimetric analysis (TGA). Both of the tensile strength and elongation length of the PVDF composite membranes were enhanced due to the addition of pineapple leaf nanocellulose and $\mathrm{g}-\mathrm{C}_{3} \mathrm{~N}_{4}$, and the tensile strength and elongation length of $\mathrm{PVDF} / \mathrm{PEG} / \mathrm{g}-\mathrm{C}_{3} \mathrm{~N}_{4} /$ Pineapple leaf nanocellulose composite membrane can reach $10.61 \mathrm{MPa}$ and $8.85 \mathrm{~mm}$. The porosity of the PVDF composite membranes was $46.6 \%$, respectively. The water flux and flux recovery

\footnotetext{
* Corresponding author at: No. 3688, Nanhai Avenue, Nanshan District, Shenzhen 518060, PR China

Email address: liuchao@szu.edu.cn (C. Liu).
} 
ratio of PVDF/PEG/g- $\mathrm{C}_{3} \mathrm{~N}_{4} /$ Pineapple leaf nanocellulose also can reach $256.75 \mathrm{~L} /\left(\mathrm{m}^{2}\right.$ .h) and up to $82.1 \%$. All the above experimental data showed that the addition of pineapple leaf nanocellulose and $\mathrm{g}-\mathrm{C}_{3} \mathrm{~N}_{4}$ can greatly improve the performance of the PVDF composite membrane. The prepared modified membrane has potential application value in the field of wastewater separation and treatment.

Keywords: poly (vinylidene fluoride) (PVDF); composite membranes; pineapple leaf nanocrystalline cellulose; $\mathrm{g}-\mathrm{C}_{3} \mathrm{~N}_{4}$.

\section{Introduction}

The world is facing environmental problems of water shortage and severe water pollution recently $[1,2]$. In this case, membrane separation has attracted people's attention as a highly efficient, energy-saving and simple operation technology [3, 4]. Poly (vinylidene fluoride) (PVDF), as an important polymer fluoride, has been widely used in the chemical stability and excellent film-forming performance [5]. And the PVDF membrane has been a hot area of research for several years. PVDF also has excellent anti-ultraviolet and anti-aging properties [6]. It is stable to ultraviolet light with a wavelength of 200-400 nm. PVDF membrane will not be brittle and cracked even if it is left outdoors for one or two decades. Due to its excellent resistance to chemical media, PVDF has excellent resistance to most inorganic acids, salts, halogens, oxidants, aliphatic, aromatic and halogenated solvents, et al [7, 8]. Its unique stability and surface properties are conducive to the compounding of PVDF with various inorganic particles, so that it is used in water treatment, gas separation membrane and other fields [9]. However, due to its low surface properties and strong hydrophobicity, PVDF has largely restricted the practical application [10].

Currently, there are many methods for preparing hydrophilic PVDF membrane, including surface coating, surface adsorption, surface plasma treatment, blending and 
copolymerization, and surface irradiation graft modification [11-13]. Therefore, the modification of PVDF membrane has attracted wide attention which mainly due to the unique electronic, magnetic, and optical properties of nanoparticles, especially in the modification of PVDF membranes by nanoparticles $[14,15]$. In recent years, $g-\mathrm{C}_{3} \mathrm{~N}_{4}$ has the advantages of low cost, simple synthesis and good chemical stability [16]. Because $\mathrm{g}-\mathrm{C}_{3} \mathrm{~N}_{4}$ has good hydrophobicity and can resist changes in the external environment, $\mathrm{g}-\mathrm{C}_{3} \mathrm{~N}_{4}$ membranes exhibit better separation performance than other commercial and inorganic membranes used for water purification [17-19]. Therefore, g- $\mathrm{C}_{3} \mathrm{~N}_{4}$ is often used as an introduced component to improve the environmental protection function and adsorption effect of the membrane [20]. Adding $g-\mathrm{C}_{3} \mathrm{~N}_{4}$ to the PVDF membrane is better than the single PVDF membrane in oilfield wastewater treatment.

Cellulose is a very attractive renewable natural polymer [21]. It is very abundant on earth and some properties not found in other natural or synthetic polymers, such as chirality, hydrophilic biodegradability, and extensive chemical modification [22]. With the emergence and development of nanotechnology, nanocellulose has become a research hotspot $[23,24]$. Pineapple is one of the most popular tropical fruits in the world and its crop occupies a prominent position in the agricultural sector. Generally speaking, nanocellulose can be separation from plant materials [25]. Nanocrystalline cellulose can be prepared by chemical, physical and microbial technology [26]. For example, in the chemical method, water and hydrogen protons in an inorganic acid are used to hydrolyze cellulose, remove amorphous regions, and break glycosidic bonds to produce nanoscale fibers [27]. Physical methods for preparing nanocrystalline cellulose include homogenization, microfluidization, microcrushing and freezing [28]. The most commonly used preparation method of nanocellulose is the homogenization 
method. But it faces the problem of homogeneous dispersion in the polymer matrix [29]. In addition, because the surface of nanocellulose is rich in hydroxyl groups, it has a strong tendency of self-association [30]. This is a problem that needs to be solved in the application. In general, nanoscale cellulose fibers are very popular for reinforcing polymers and enhancing hydrophilic materials for preparing composite materials.

This study aims to study a simple method to improve the hydrophilicity, separation and antifouling properties of PVDF membranes. A simple non-solvent induced phase separation (NIPS) strategy was used to design and prepare pineapple leaf nanocellulose and $\mathrm{C}_{3} \mathrm{~N}_{4}$ or $\mathrm{g}-\mathrm{C}_{3} \mathrm{~N}_{4}$ modified PVDF membranes with interpenetrating network nanoarchitectonics and water channels. This work shows that the nano-materials can improve the hydrophilicity of the PVDF composite membranes by blending pineapple leaf nanocrystalline cellulose with $\mathrm{g}-\mathrm{C}_{3} \mathrm{~N}_{4}$. The prepared PVDF composite membranes were characterized by FTIR, SEM, TGA, XRD, and hydrophilicity (pure water flux and dynamic contact angle). In addition, the mechanical properties of the prepared membrane were quantified, and the effect of adding pineapple leaf nanocellulose and $\mathrm{C}_{3} \mathrm{~N}_{4}$ or $\mathrm{g}-\mathrm{C}_{3} \mathrm{~N}_{4}$ was analyzed. Finally, the focus is on the antifouling properties of the prepared membrane, which provides valuable enlightenment for potential engineering treatment applications.

\section{Experimental section}

\subsection{Materials}

Commercially available PVDF (FR904) was dried at $60{ }^{\circ} \mathrm{C}$ overnight before further use. Pineapple leaf was obtained from South Subtropical Crop Research Institute, China Academy of Tropical Agricultural Sciences. N, N-dimethylformamide (DMF), polyethylene glycol (PEG 6000) and melamine were purchased from Sinopharm chemical reagent Co., Ltd., Shanghai. Bovine serum albumin (BSA) was 
purchased from Shanghai Aladdin Bio-Chem Technology Co., Ltd., China. All of the used chemicals were of analytical grade without further purification.

\subsection{Preparation of the PVDF composite Membranes}

Graphite phase g- $\mathrm{C}_{3} \mathrm{~N}_{4}$ was prepared by a common method [31]. Using melamine as raw material, $10 \mathrm{~g}$ of melamine was uniformly ground and placed in a semi-closed crucible. It was placed in a muffle furnace and heated to $550{ }^{\circ} \mathrm{C}$ at $2.5^{\circ} \mathrm{C} / \mathrm{min}$ for $4 \mathrm{~h}$. The muffle furnace was closed, cooled and taken it out, and the yellow solid was ground into a powder to obtain a graphite phase $\mathrm{g}-\mathrm{C}_{3} \mathrm{~N}_{4}$. The treated pineapple leaf were immersed in $\mathrm{H}_{2} \mathrm{SO}_{4}(15 \mathrm{wt} \%)$ solution, thoroughly mixed with an electric stirrer, and reacted at $85^{\circ} \mathrm{C}$. At the end of the reaction, the $\mathrm{pH}$ of the solution was adjusted to neutral using deionized water. After separated and dried, immersed the solid in DMAc, a high-pressure homogenizer was used. Subsequently, a colloidal suspension of nanocrystalline cellulose was obtained. The various PVDF composite membranes were obtained by using a non-solvent induced phase separation (NIPS) technique. The casting solution consisted of $16 \mathrm{wt} \%$ PVDF and $1.0 \mathrm{wt} \%$ PEG 6000, $0.5 \mathrm{wt} \%$ nanocrystalline cellulose and $0.5 \mathrm{wt} \% \mathrm{C}_{3} \mathrm{~N}_{4}$ or g- $\mathrm{C}_{3} \mathrm{~N}_{4}$. PVDF, PEG, Pineapple leaf nanocellulose, $\mathrm{C}_{3} \mathrm{~N}_{4}$ or $\mathrm{g}-\mathrm{C}_{3} \mathrm{~N}_{4}$ were dissolved in DMF under rigorous stirring at $60{ }^{\circ} \mathrm{C}$ for $24 \mathrm{~h}$, and the casting solution was spread onto the glass plate using a blade (Scheme 1). Then, the glass plate was immersed into a water bath for $24 \mathrm{~h}$ before using. 


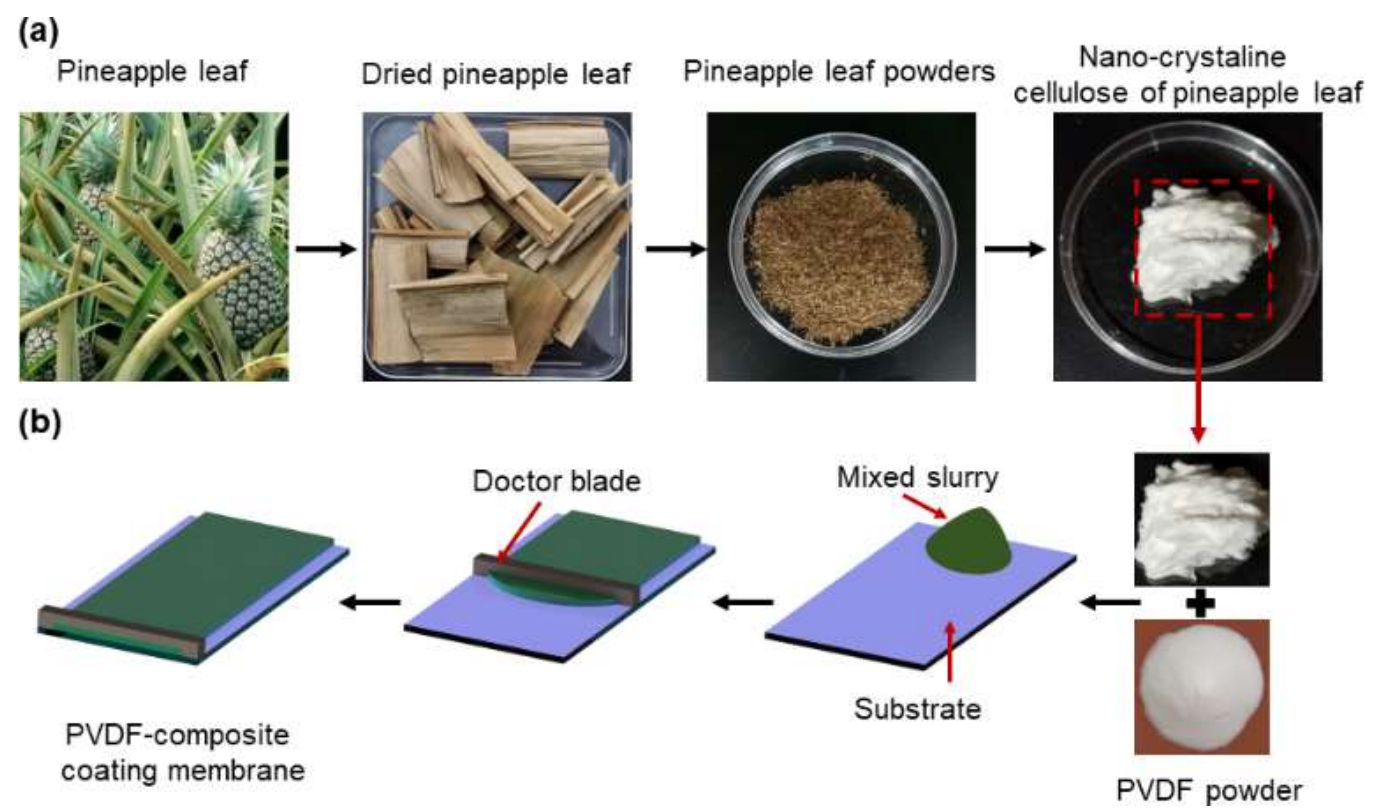

Scheme 1. Preparation of PVDF membranes blended with nanocrystalline cellulose and $\mathrm{g}_{-} \mathrm{C}_{3} \mathrm{~N}_{4}$.

\subsection{Membrane characterization}

Fourier transform infrared (FT-IR) spectroscopy (PerkinElmer, Spectra One, USA) was used to evaluate the stability of the PVDF composite membranes at room temperature within the range $550-4000 \mathrm{~cm}^{-1}$ of the wave number. The surface morphology of the PVDF composite membranes were evaluated by the S-3400 SEM (Tokyo, Japan) at $20 \mathrm{kV}$. To obtain the crystallinity of the PVDF composite membranes,

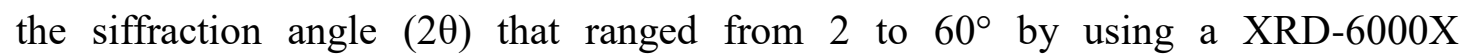
diffractometer with $\mathrm{Cu} \mathrm{Ka}$ X-radiation. The thermal stability of the composite membrane and nanocrystalline cellulose were analyzed by a thermogravimetric analyzer system (Sta 449c, Netzch, Germany). The test temperature range is $100-800$ ${ }^{\circ} \mathrm{C}$, and the heating rate is $10{ }^{\circ} \mathrm{C} / \mathrm{min}$. Instron 5569 Material Testing Instrument was used to evaluate the mechanical properties of the PVDF composite membranes with the speed of $10 \mathrm{~mm} / \mathrm{min}$ at room temperature. The surface hydrophilicity of the PVDF composite membrane was measured by a contact angle measuring device (SL2008, Shanghai Solon Technology Co., Ltd.). The porosity of the membrane were tested according to the method provided by Zhang et al's method [32]. A membrane with a 
known area was weighed in a hygroscopic state and immediately dried in an oven. Porosity is evaluated by the following equation:

$$
P_{r}=\frac{G_{w}-G_{d}}{d_{w} \times A_{m} \times L_{m}}
$$

where $G_{w}$ is weight of the wet membrane $(g) ; G_{d}$ is weight of the dry membrane $(g)$; $d_{w}$ is the density of water $\left(\mathrm{g} / \mathrm{cm}^{3}\right) ; \mathrm{A}_{\mathrm{m}}$ and $\mathrm{L}_{\mathrm{m}}$ are the membrane area $\left(\mathrm{cm}^{2}\right)$ and thickness (cm), respectively.

\subsection{Pure water flux and antifouling properties of the PVDF composite membranes}

The pure water flux was measured according to the previous method [33]. In order to data collection, the various PVDF composite membranes were compacted with deionized water at a working pressure of $0.1 \mathrm{MPa}$ for $30 \mathrm{~min}$. Then, the pure water flux $\left[\mathrm{JW}\left(\mathrm{L} /\left(\mathrm{m}^{2} \cdot \mathrm{h}\right)\right)\right]$ were obtained by the following equation:

$$
J_{w}=\frac{\mathrm{V}}{\mathrm{S} \times \mathrm{t}}
$$

where $\mathrm{V}$ is the volume of pure water penetrated through the various PVDF composite membranes (L), $\mathrm{S}$ is the effective membrane area $\left(\mathrm{m}^{2}\right)$ and $\mathrm{t}$ is the time of working $(\mathrm{h})$.

The selectivity of the various PVDF composite membrane was then determined with BSA solution $(1 \mathrm{~g} / \mathrm{L})$ under stirring. Four comparison parameters, namely, flux recovery ratio (FRR), irreversible flux decline ratio (DRir), reversible flux decline ratio (DRr), and total flux decline ratio (FDR), were introduced for detailed comparison of antifouling performance [34]. The antifouling properties of various PVDF composite membrane were calculated using the following equation:

$$
\begin{gathered}
F R R=\frac{J_{3}}{J_{1}} \times 100 \% \\
D R_{\mathrm{ir}}=\left(1-\frac{J_{3}}{J_{1}}\right) \times 100 \% \\
D R_{\mathrm{r}}=\left(\frac{J_{3}-J_{2}}{J_{1}}\right) \times 100 \%
\end{gathered}
$$




$$
F D R=\left(1-\frac{J_{2}}{J_{1}}\right) \times 100 \%
$$

Where $J_{1}$ is the pure water flux, $J_{2}$ is the $4 \mathrm{~h}$ of BSA foulant liquid filtration flux and $J_{3}$ is the water flux for a $1 \mathrm{~h}$ under the same operating pressure was retested after washing.

\section{Results and discussion}

\subsection{Membrane characterization}

The FT-IR spectra of various PVDF composite membranes with pineapple leaf nanocellulose, $\mathrm{C}_{3} \mathrm{~N}_{4}$, and $\mathrm{g}-\mathrm{C}_{3} \mathrm{~N}_{4}$ were shown in Fig. 1. The chemical structure of pure PVDF and PVDF/PEG membranes was exhibited in Fig. 1(a) and (b). The bands located at 3080 and $2864 \mathrm{~cm}^{-1}$ related to the $\mathrm{CH}_{2}$ asymmetric and symmetric vibration of the PVDF. Meanwhile, there were differences between Fig. 1(a) and (c). A peak at $3348 \mathrm{~cm}^{-1}$ could be observed in Fig. 1(c) which has lower peak strength than found in Fig. 1(a). The occurrence of the new absorption peak was attributed to $\mathrm{O}-\mathrm{H}$ stretching vibration of cellulose. It indicated that the molecule of pineapple leaf nanocellulose was existed in the PVDF composite membranes. Moreover, a weak band at $3347 \mathrm{~cm}^{-1}$ appeared in the PVDF/PEG/ $\mathrm{C}_{3} \mathrm{~N}_{4}$ and $\mathrm{PVDF} / \mathrm{PEG} / \mathrm{C}_{3} \mathrm{~N}_{4} /$ Pineapple leaf nanocellulose membrane (Fig.1 (d), (e) and (f)), which may be related to the N-H stretching mode of $\mathrm{C}_{3} \mathrm{~N}_{4}$. This phenomenon can be seen that $\mathrm{C}_{3} \mathrm{~N}_{4}$ has also been distributed on the surface of PVDF. 


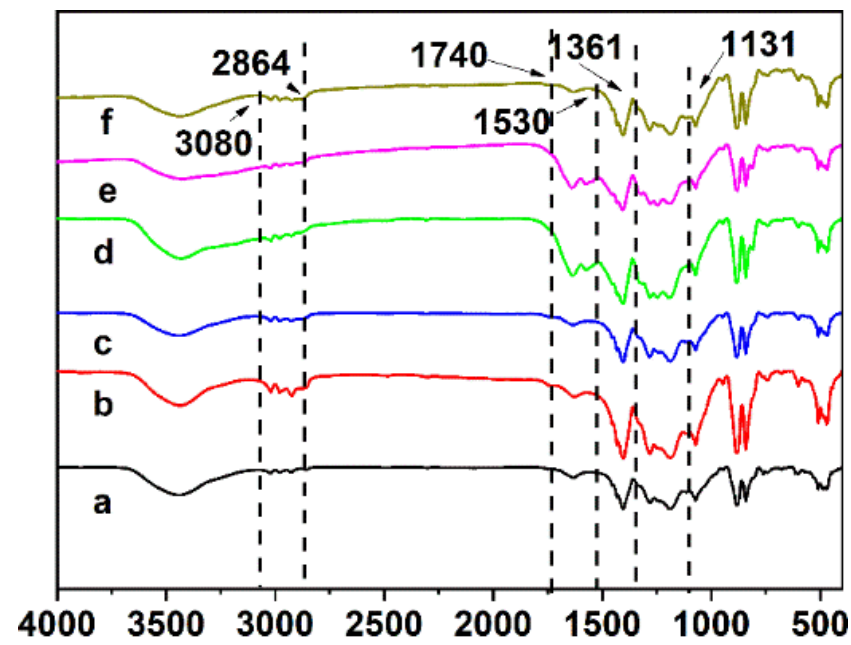

Wave number $\left(\mathrm{cm}^{-1}\right)$

Fig.1. FTIR spectra of (a) pure PVDF, (b) PVDF/PEG, (c) PVDF/PEG/Pineapple leaf nanocellulose, (d) $\mathrm{PVDF} / \mathrm{PEG} / \mathrm{C}_{3} \mathrm{~N}_{4}$, (e) $\mathrm{PVDF} / \mathrm{PEG} / \mathrm{C}_{3} \mathrm{~N}_{4} /$ Pineapple leaf nanocellulose and (f) PVDF/PEG/g-C $\mathrm{N}_{4} /$ Pineapple leaf nanocellulose composite membranes.

As shown in Fig. 2a-f, the surface morphology of the various PVDF composite membranes with different components was depicted by SEM images. Compared with the pure PVDF membrane, the PVDF/PEG/Pineapple leaf nanocellulose composite membrane (Fig. 2c) have more surface bubbles than pure PVDF membranes (Fig. 2a) which mainly attributed to the presence of pineapple leaf nanocellulose accelerates the process of water penetration into the solution. As shown in Fig. $2 \mathrm{f}$, more distributed holes appeared on the surface of the PVDF/PEG/g- $\mathrm{C}_{3} \mathrm{~N}_{4} /$ Pineapple leaf nanocellulose composite membranes. The cross-sectional view of all sample shown the typical asymmetric structure, and an irregular cross-sectional fracture surface with many open voids. For this porous structure, it has an enhancement effect on promoting the pure water flux of the PVDF composite membrane. 

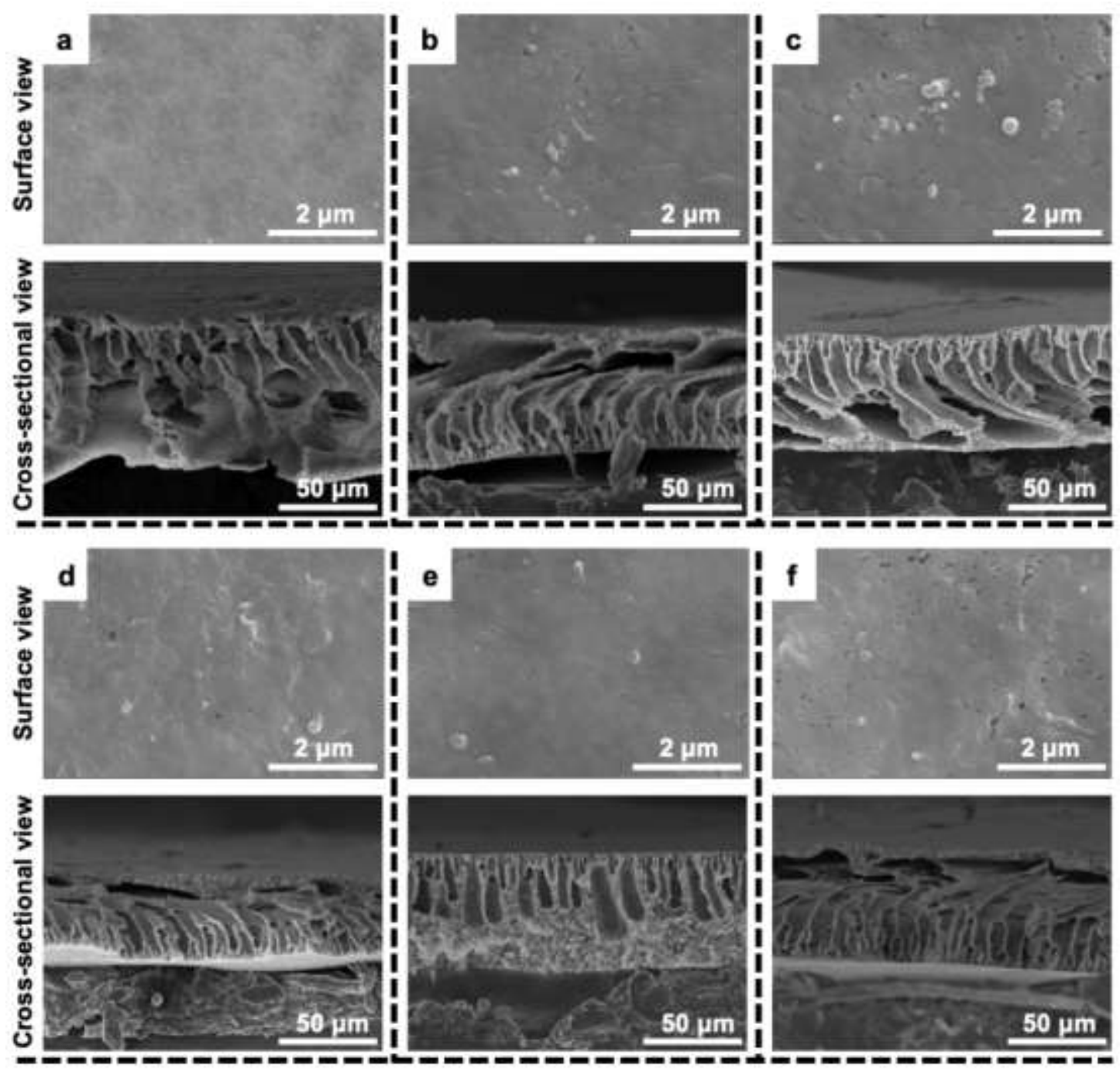

Fig.2. SEM images of (a) pure PVDF, (b) PVDF/PEG, (c) PVDF/PEG/Pineapple leaf nanocellulose, (d) $\mathrm{PVDF} / \mathrm{PEG} / \mathrm{C}_{3} \mathrm{~N}_{4}$, (e) $\mathrm{PVDF} / \mathrm{PEG} / \mathrm{C}_{3} \mathrm{~N}_{4} /$ Pineapple leaf nanocellulose and (f) $\mathrm{PVDF} / \mathrm{PEG} / \mathrm{g}-\mathrm{C}_{3} \mathrm{~N}_{4} /$ Pineapple leaf nanocellulose composite membranes.

The crystal structures of the various PVDF composite membranes were shown in Fig. 3. As shown in Fig. 3a-f, an obvious peak at $2 \theta=20.1^{\circ}$ which related to the crystalline peaks of PVDF $\boldsymbol{\alpha}$ crystalline phase [35]. A weak peak at $2 \theta=27.5^{\circ}$ was observed in Fig. 3d-f, which correspond to the in-plane structure packing motif and the interlayer stacking of the aromatic system of $\mathrm{C}_{3} \mathrm{~N}_{4}$ and $g-\mathrm{C}_{3} \mathrm{~N}_{4}$ [36]. It can be seen a weak peak at $2 \theta=18.3^{\circ}$ (Fig. 3 (e)), which may be related to the crystallographic planes, respectively and the peaks could be attributed to cellulose I, which had a monoclinic structure. These characteristic peaks are attributed to the crystal plane of 
nanocrystalline cellulose and $\mathrm{g}-\mathrm{C}_{3} \mathrm{~N}_{4}$, indicating that nanocrystalline cellulose and g- $\mathrm{C}_{3} \mathrm{~N}_{4}$ exist in the PVDF/PEG/g- $\mathrm{C}_{3} \mathrm{~N}_{4} /$ Pineapple leaf nanocellulose composite membrane.

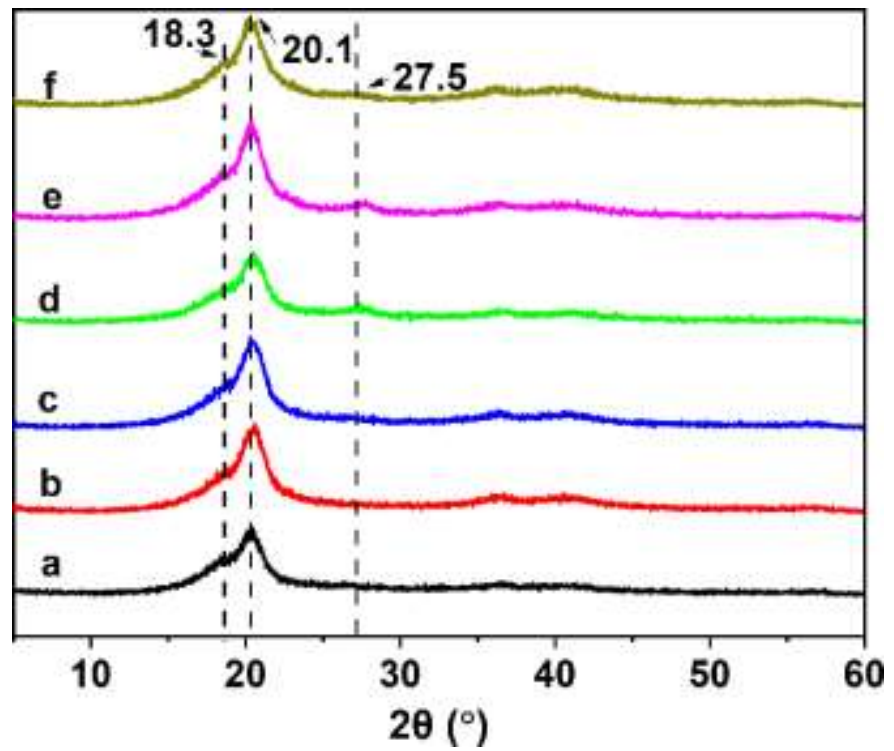

Fig.3. XRD patterns of (a) pure PVDF, (b) PVDF/PEG, (c) PVDF/PEG/Pineapple leaf nanocellulose, (d) $\mathrm{PVDF} / \mathrm{PEG} / \mathrm{C}_{3} \mathrm{~N}_{4}$, (e) $\mathrm{PVDF} / \mathrm{PEG} / \mathrm{C}_{3} \mathrm{~N}_{4} /$ Pineapple leaf nanocellulose and (f) $\mathrm{PVDF} / \mathrm{PEG} / \mathrm{g}-\mathrm{C}_{3} \mathrm{~N}_{4} /$ Pineapple leaf nanocellulose composite membranes.

The TGA curve of various PVDF composite membranes was shown in Fig. 4. Due to the difference in chemical composition, the different PVDF composite membranes were decomposed at different temperatures [13]. The thermal decomposition of the pure PVDF membrane was mainly occurs at $450-500{ }^{\circ} \mathrm{C}$ (Fig. 4a). At the same time, a two weightlessness steps were observed in curve (Fig. 4c-f). The first weight loss stage was observed at $330-420$ or $450{ }^{\circ} \mathrm{C}$ which mainly attributed to the thermal decomposition of pineapple leaf nanocrystalline cellulose or $\mathrm{C}_{3} \mathrm{~N}_{4}$ (Fig. $4 \mathrm{c}$ and d) and the second weight loss stage observed at 440 to 480 or $450-400^{\circ} \mathrm{C}$ which mainly due to the thermal decomposition of pure PVDF. Meanwhile, we can clearly observe that the $\mathrm{PVDF} / \mathrm{PEG} / \mathrm{C}_{3} \mathrm{~N}_{4} /$ Pineapple leaf nanocellulose composite membranes (Fig. $4 \mathrm{e}$ ) has a lower weight loss than PVDF/PEG/g- $\mathrm{C}_{3} \mathrm{~N}_{4} /$ Pineapple leaf nanocellulose composite membranes (Fig. 4f) which mainly attributed to the thermal decomposition of $\mathrm{C}_{3} \mathrm{~N}_{4}$ and 
g- $\mathrm{C}_{3} \mathrm{~N}_{4}$. All the results shown that the weight loss of the various PVDF composite membranes has a better thermal stability under $330{ }^{\circ} \mathrm{C}$.

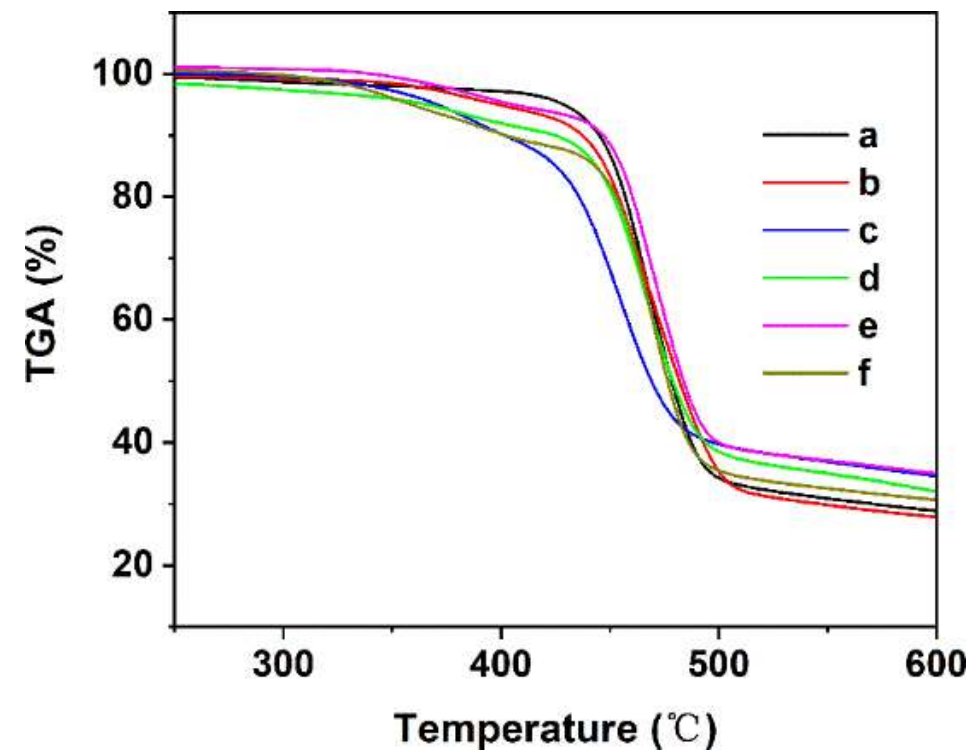

Fig. 4. TGA Curves of (a) pure PVDF, (b) PVDF/PEG, (c) PVDF/PEG/Pineapple leaf nanocellulose, (d) $\mathrm{PVDF} / \mathrm{PEG} / \mathrm{C}_{3} \mathrm{~N}_{4}$, (e) $\mathrm{PVDF} / \mathrm{PEG} / \mathrm{C}_{3} \mathrm{~N}_{4} /$ Pineapple leaf nanocellulose and (f) $\mathrm{PVDF} / \mathrm{PEG} / \mathrm{g}-\mathrm{C}_{3} \mathrm{~N}_{4} /$ Pineapple leaf nanocellulose composite membranes.

\subsection{The hydrophilicity of the PVDF composite membranes}

The hydrophilicity of the various PVDF composite membranes was characterized by measuring contact angle. According to the Table 1, the contact angle of the various PVDF composite membranes had been reduced as time go on. Moreover, the hydrophilicity of the various PVDF composite membrane also can be improved by adding pineapple leaf nanocellulose which mainly due to its hydrophilic functional groups such as hydroxyl groups. Besides, adding the pineapple leaf nanocellulose, $\mathrm{C}_{3} \mathrm{~N}_{4}$ or g- $\mathrm{C}_{3} \mathrm{~N}_{4}$ also can form a higher surface porosity and lead to a slightly decrease in the contact angle. Higher surface total energy and adhesion mean that the membrane surface has strong polarity and hydrophilicity [37], and the results of modified membranes was higher than that of primary PVDF membrane (Table 1). Therefore, the PVDF composite membranes were effectively improved by adding the pineapple leaf nanocellulose, $\mathrm{C}_{3} \mathrm{~N}_{4}$ or $\mathrm{g}-\mathrm{C}_{3} \mathrm{~N}_{4}$. 
Table 1. The hydrophilicity of (a) pure PVDF, (b) PVDF/PEG, (c) PVDF/PEG/Pineapple leaf nanocellulose, (d) $\mathrm{PVDF} / \mathrm{PEG} / \mathrm{C}_{3} \mathrm{~N}_{4}$, (e) $\mathrm{PVDF} / \mathrm{PEG} / \mathrm{C}_{3} \mathrm{~N}_{4} /$ Pineapple leaf nanocellulose and (f) $\mathrm{PVDF} / \mathrm{PEG} / \mathrm{g}-\mathrm{C}_{3} \mathrm{~N}_{4} /$ Pineapple leaf nanocellulose composite membranes.

\begin{tabular}{|c|c|c|c|c|c|c|c|}
\hline \multirow{2}{*}{ Membrane } & \multicolumn{4}{|c|}{ Contact Angle $\left({ }^{\circ}\right)^{\mathrm{a}}$} & \multirow{2}{*}{$\begin{array}{c}\text { Surface } \\
\text { energy } \\
\left(\mathrm{mJ} \mathrm{m}^{-2}\right)\end{array}$} & \multirow{2}{*}{$\begin{array}{c}\text { Adhesion } \\
\text { work } \\
\left(\mathrm{mN} \mathrm{m}^{-1}\right)\end{array}$} & \multirow{2}{*}{ Fig. } \\
\hline & Initial & $30 \mathrm{~s}$ & $60 \mathrm{~s}$ & $90 \mathrm{~s}$ & & & \\
\hline $\mathrm{a}$ & 94.13 & 81.97 & 81.40 & 80.52 & 27.39 & 69.06 & \\
\hline $\mathrm{b}$ & 81.77 & 77.67 & 74.81 & 71.82 & 34.75 & 83.99 & \\
\hline $\mathrm{c}$ & 61.82 & 58.73 & 52.72 & 39.35 & 46.83 & 107.36 & \\
\hline d & 73.73 & 71.90 & 65.17 & 57.78 & 39.40 & 93.20 & \\
\hline $\mathrm{e}$ & 68.55 & 64.25 & 55.60 & 55.26 & 44.35 & 102.73 & \\
\hline $\mathrm{f}$ & 70.08 & 61.61 & 57.02 & 52.77 & 42.42 & 99.06 & \\
\hline
\end{tabular}

${ }^{\text {a }}$ Error in contact angle measurement is $<1.0^{\circ}$.

\subsection{Mechanical properties of the PVDF composite membranes}

The thickness of various PVDF composite membranes was shown in Fig. 5 (left).

The thickness of the various PVDF composite membranes is between $0.045-0.06 \mathrm{~mm}$, and the differences in thickness of the membranes are small. Therefore, the addition of nanomaterials did not cause significant changes in thickness. The effects of pure PVDF, PVDF/PEG, PVDF/PEG/Pineapple leaf nanocellulose, PVDF/PEG/ $\mathrm{C}_{3} \mathrm{~N}_{4}$, $\mathrm{PVDF} / \mathrm{PEG} / \mathrm{C}_{3} \mathrm{~N}_{4} /$ Pineapple leaf nanocellulose and PVDF/PEG/g- $\mathrm{C}_{3} \mathrm{~N}_{4} /$ Pineapple leaf nanocellulose membranes on the porosity was listed in Fig. 5 (right). The porosity of the PVDF composite membranes were increased with the addition of different substances. The porosity of the prepared the PVDF composite membrane is in the range of $10 \%$ to $33 \%$. The peak value of porosity is $32.6 \%$. Pineapple leaf nanocellulose is a hydrophilic material with a large num ber of hydrophilic groups which can accelerate the diffusion process between gels (water) and solvent (DMF) in the PVDF composite membrane preparation process. Then, the PVDF/PEG/Pineapple leaf nanocellulose membrane has relatively higher porosity than pure PVDF membrane. However, the $\mathrm{C}_{3} \mathrm{~N}_{4}$ have some negative effects on the porosity of the PVDF composite membrane which mainly attributed to its hydrophobic properties. Besides, the porosity of the $\mathrm{PVDF} / \mathrm{PEG} / \mathrm{g}-\mathrm{C}_{3} \mathrm{~N}_{4} /$ Pineapple leaf nanocellulose composite membranes also has been 
strength by adding $\mathrm{g}-\mathrm{C}_{3} \mathrm{~N}_{4}$. Therefore, the presence of pineapple leaf nanocellulose and g- $\mathrm{C}_{3} \mathrm{~N}_{4}$ may facilitate the formation membranes with high porosity.
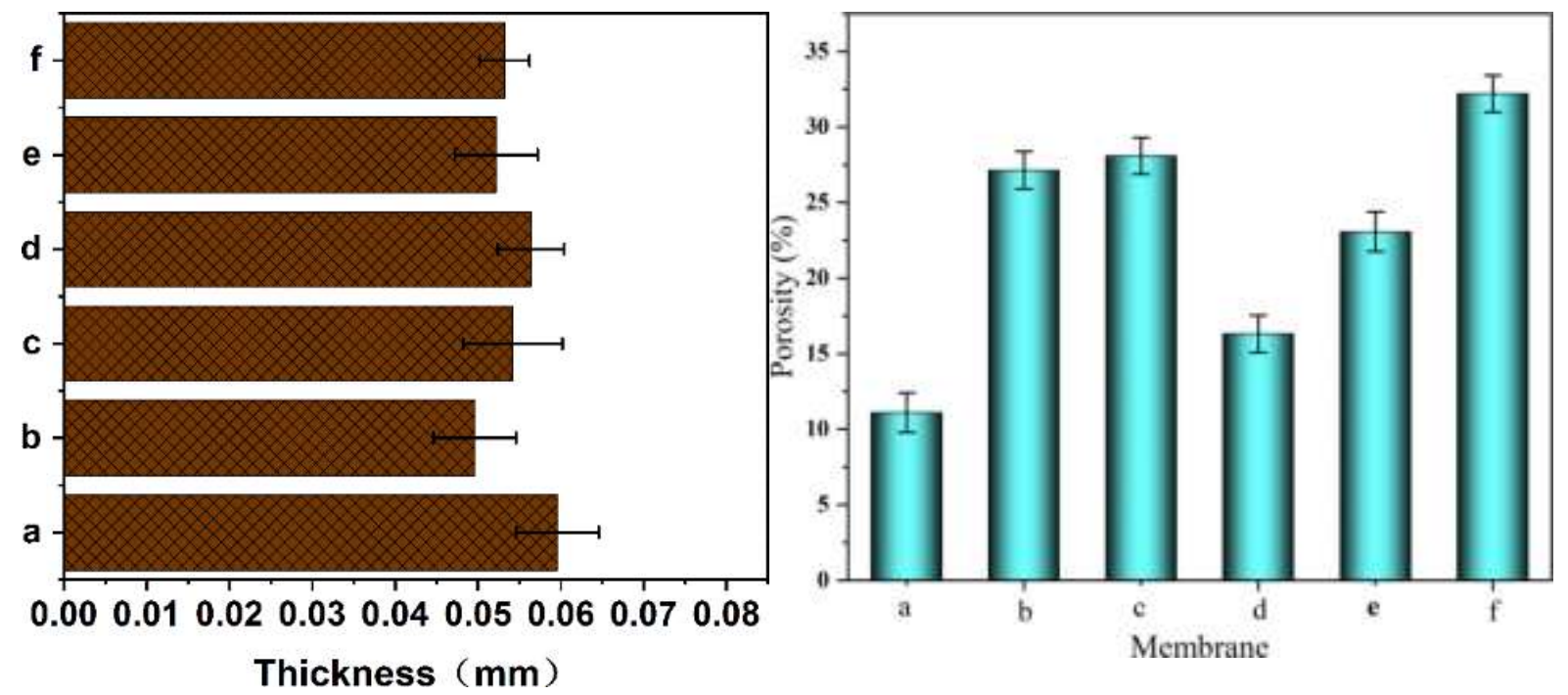

Fig. 5. The thickness (left) and porosity (right) of (a) pure PVDF, (b) PVDF/PEG, (c) PVDF/PEG/Pineapple leaf nanocellulose, (d) PVDF/PEG/C ${ }_{3} \mathrm{~N}_{4}$, (e) PVDF/PEG/ $\mathrm{C}_{3} \mathrm{~N}_{4} /$ Pineapple leaf nanocellulose and (f) PVDF/PEG/g- $\mathrm{C}_{3} \mathrm{~N}_{4} /$ Pineapple leaf nanocellulose composite membranes.

The tensile strength of the various PVDF composite membranes was shown in Fig. 6. Compared to the pure PVDF membrane, the tensile strength of the other PVDF composite membrane had a slightly decreased by adding $\mathrm{C}_{3} \mathrm{~N}_{4}, \mathrm{~g}-\mathrm{C}_{3} \mathrm{~N}_{4}$ or pineapple leaf nanocellulose at different extents, but in a tolerable degree. The reason for this phenomenon is that the PEG, as a pore-forming agent, will dissolved into the water and form the pore in the PVDF composite membrane which can reduces the cross-sectional area for resisting external forces. However, duo to the excellent mechanical properties and hydrophilicity of nanomaterials, the tensile strength of the other PVDF composite membrane also has been improved to some extent by adding the pineapple leaf nanocellulose, $\mathrm{C}_{3} \mathrm{~N}_{4}$ or $\mathrm{g}-\mathrm{C}_{3} \mathrm{~N}_{4}$ in the casting solution. Table 2 shows the further benchmark comparison between the selected PVDF/PEG/g- $\mathrm{C}_{3} \mathrm{~N}_{4} /$ Pineapple leaf nanocellulose membrane and other modified PVDF membranes reported in the literature. Obviously, the membrane in this work has excellent tensile strength, elongation and hydrophilicity, indicating its good practical application potential. 


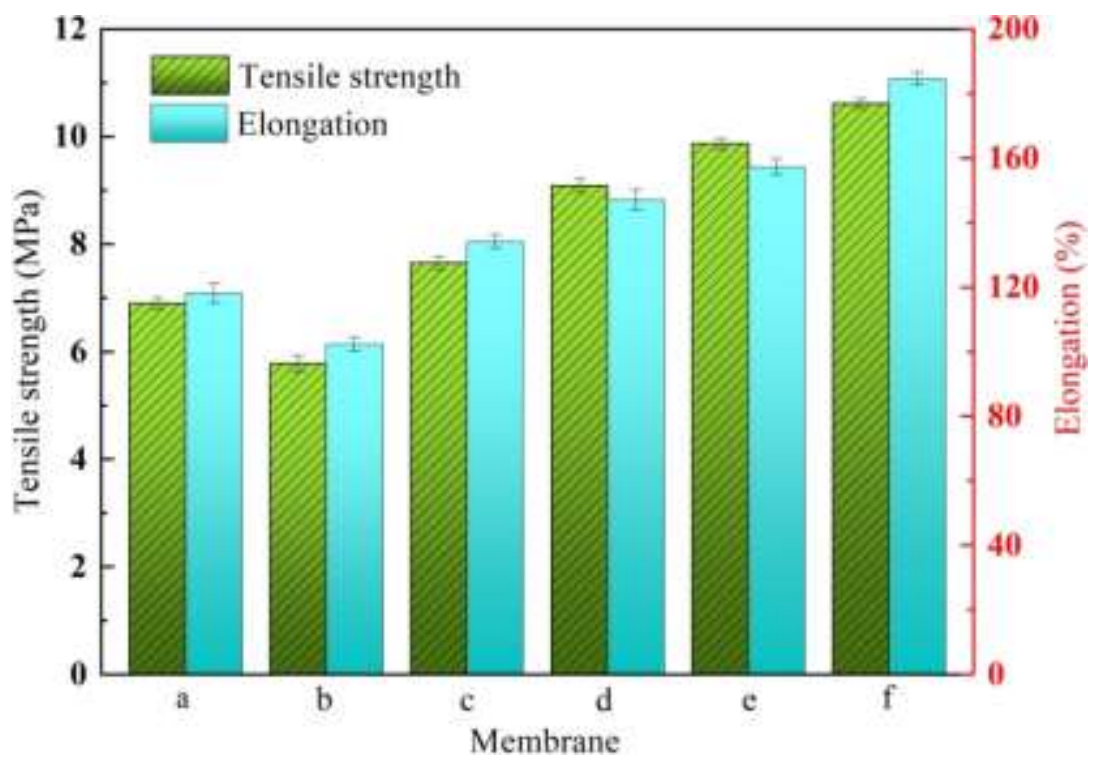

Fig. 6. Mechanical properties of (a) pure PVDF, (b) PVDF/PEG, (c) PVDF/PEG/Pineapple leaf nanocellulose, (d) $\mathrm{PVDF} / \mathrm{PEG} / \mathrm{C}_{3} \mathrm{~N}_{4}$, (e) $\mathrm{PVDF} / \mathrm{PEG} / \mathrm{C}_{3} \mathrm{~N}_{4} /$ Pineapple leaf nanocellulose and (f) $\mathrm{PVDF} / \mathrm{PEG} / \mathrm{g}-\mathrm{C}_{3} \mathrm{~N}_{4} /$ Pineapple leaf nanocellulose composite membranes.

Table 2 Comparison of hydrophilicity and mechanical properties of the various PVDF membranes.

\begin{tabular}{|c|c|c|c|c|c|}
\hline Membrane & Method & $\begin{array}{r}\begin{array}{r}\text { Tensile } \\
\text { strength }\end{array} \\
(\mathrm{MPa})\end{array}$ & $\frac{\text { Elongation }}{(\%)}$ & $\begin{array}{l}\text { Contact } \\
\text { angles }^{\mathrm{a}} \\
\left(^{\circ}\right)\end{array}$ & Reference \\
\hline PVDF & NIPS & 6.2 & 118.1 & 88.5 & {$[38]$} \\
\hline PVDF/PVP & TIPS & 5.2 & $\sim 340^{\mathrm{b}}$ & 89.0 & [39] \\
\hline PVDF/PTFE & TIPS & 7.4 & $\sim 180^{\mathrm{b}}$ & 106.0 & {$[40]$} \\
\hline $\begin{array}{c}\text { F127/PTFE } \\
\text { (TP1F1) }\end{array}$ & TIPS & 7.0 & 170.0 & 76.0 & [41] \\
\hline PVDF-g-PEG & NIPS & 8.5 & $\sim 131^{b}$ & 61.6 & [42] \\
\hline $\mathrm{PVDF} / \mathrm{CaCO}_{3}$ & NIPS & 5.7 & 126.8 & 107.8 & [43] \\
\hline $\begin{array}{c}\text { PVDF/PEG/g- } \mathrm{C}_{3} \mathrm{~N} \\
{ }_{4} / \mathrm{Pineapple} \mathrm{leaf} \\
\text { nanocellulose }\end{array}$ & NIPS & 10.6 & 184.5 & 68.5 & This work \\
\hline
\end{tabular}

${ }^{\mathrm{a}}$ The contact angle error does not exceed $0.5^{\circ}$.

${ }^{\mathrm{b}}$ The data was collected from graphs in the literature by using the digitizer function.

\subsection{Separation and antifouling properties of the PVDF composite membranes}

To evaluate the filtering performance of the PVDF composite membrane, the pure water flux and rejection ratio were measured, as shown in Fig.7A Compared to the pure PVDF and PVDF/PEG, the pure water flux was significantly enhanced by adding 
pineapple leaf nanocellulose which also attributed to its large specific surface area and abundant hydroxyl groups. Pineapple leaf nanocellulose can enhance the permeability of PVDF membrane by accelerating the transient phase separation process on the surface of the PVDF composite membrane. The water flux of the PVDF/PEG/g- $\mathrm{C}_{3} \mathrm{~N}_{4} /$ Pineapple leaf nanocellulose membrane reached a peak of 256.75 $\mathrm{L} /\left(\mathrm{m}^{2} \cdot \mathrm{h}\right)$. Time-dependent normalized flux in the BSA-fouled was plotted in Fig.7B. When the BSA dirt solution was filtered, the membrane flux drops sharply attribute to the adsorption and deposition, but the degree of decline and the flux recovery ratio (FRR, $J_{3} / J_{1}$ ) were different. The FRR ratios of PVDF/PEG/C $3 \mathrm{~N}_{4} /$ Pineapple leaf nanocellulose and PVDF/PEG/g- $\mathrm{C}_{3} \mathrm{~N}_{4} /$ Pineapple leaf nanocellulose composite membranes were $77.8 \%$ and $82.1 \%$, respectively, which are much higher than $41.8 \%$ of the pure PVDF membrane (1.8 and 2.0 times, respectively). The $\mathrm{PVDF} / \mathrm{PEG} / \mathrm{C}_{3} \mathrm{~N}_{4} /$ Pineapple leaf nanocellulose and PVDF/PEG/g- $\mathrm{C}_{3} \mathrm{~N}_{4} /$ Pineapple leaf nanocellulose composite membranes still show excellent anti-fouling properties after repeating the scale test three times with BSA solution (Fig.7C). Fig.7D presents the total flux decline ratio (FDR), irreversible (DRir), reversible (DRr) fouling resistance ratios of the prepared membranes. The FDR ratios of PVDF/PEG/ $\mathrm{C}_{3} \mathrm{~N}_{4} /$ Pineapple leaf nanocellulose and PVDF/PEG/g- $\mathrm{C}_{3} \mathrm{~N}_{4} /$ Pineapple leaf nanocellulose composite membranes were $65.2 \%$ and $66.8 \%$, respectively, which were much lower than the $85.2 \%$ of pure PVDF membranes. The main difference in the anti-fouling properties of the prepared membranes was the DRir ratio $(12.2 \%, 27.3 \%$ and $28.4 \%$, respectively), indicating that the addition of $\mathrm{C}_{3} \mathrm{~N}_{4} / \mathrm{g}_{-} \mathrm{C}_{3} \mathrm{~N}_{4}$ and pineapple leaf nanocellulose active suppressions the irreversible contamination, thus significantly enhanced the anti-fouling property of the PVDF membrane. For PVDF hydrophobic membrane, contaminants (such as proteins and sugars, etc.) may be bound to the large 
pores or adsorbed to the channels, hindering their removal through hydraulic washing. This irreversible membrane fouling leads to a decrease in the water flux recovery rate after hydraulic washing. In this study, the hydrophilic groups in the $\mathrm{C}_{3} \mathrm{~N}_{4} / g-\mathrm{C}_{3} \mathrm{~N}_{4}$ and pineapple leaf nanocellulose particles in the prepared membrane interact with the water layer in the aqueous solution, which may hinder the deposition and adsorption of contamination on the membrane surface. Furthermore, the formed hydration layer may stabilize the structure of the protein to ensure that no obvious conformational changes occur during the adsorption process, which leads to reversible desorption. The results show that the prepared modified PVDF membrane has excellent antifouling performance and the water flux was higher than that of pure PVDF membrane.

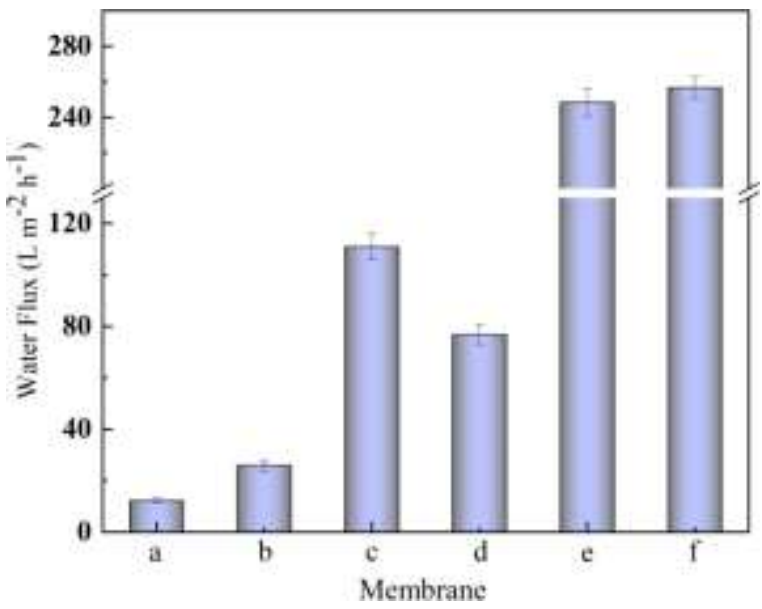

(A)

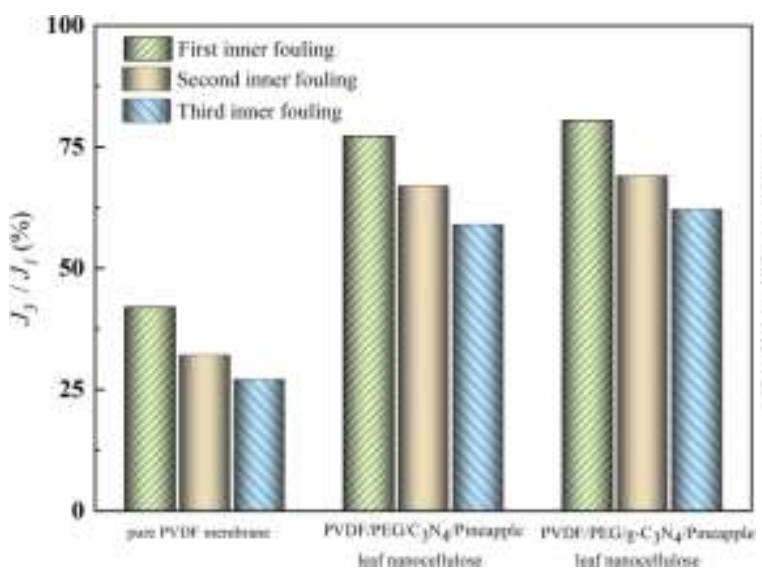

(C)

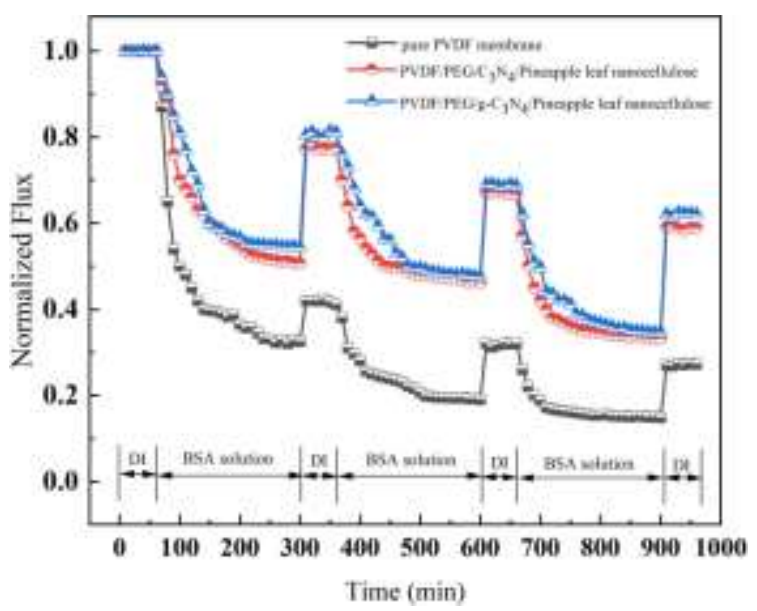

(B)

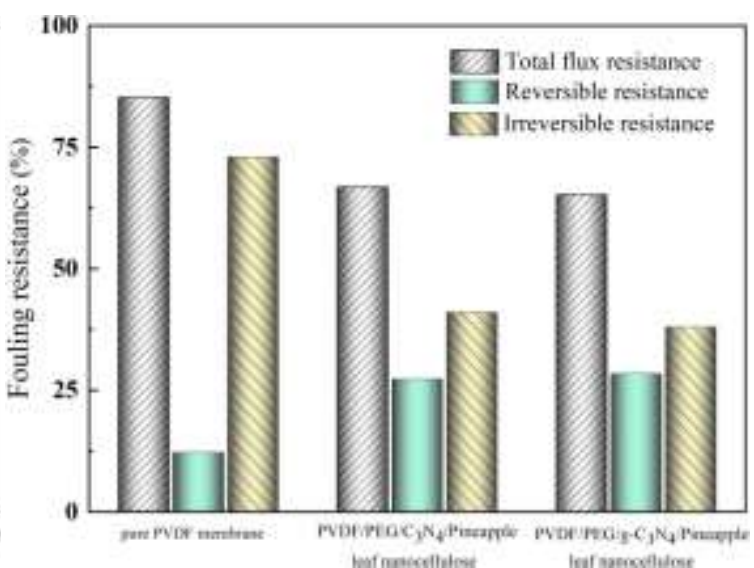

(D)

Fig. 7. The (A) pure water flux and (B) time-dependent normalized flux in the BSA-fouled of the 
prepared membrane. Antifouling properties: (C) water flux recovery ratio and (D) fouling resistance.

\section{Conclusions}

In summary, the PVDF composite membranes were prepared through non-solvent induced phase separation technique with nanocellulose and $\mathrm{g}-\mathrm{C}_{3} \mathrm{~N}_{4}$ were used as non-solvent additives in this work. Pineapple leaf nanocellulose and g- $\mathrm{C}_{3} \mathrm{~N}_{4}$ was well dispersed in the PVDF composite membrane matrix and confirmed via FTIR, SEM, XRD, and TGA analyses. The addition of nanoparticles effectively improves the hydrophilicity of the membrane, and forms nano-scale water channels between the separation layers of the PVDF membrane, which effectively promotes water penetration. At the same time, the prepared composite membrane has the dual functions of surface hydrophilic modifier and pore former. These characteristics make the prepared PVDF composite membranes have higher hydrophilicity, and increase the filtration and antifouling properties of the membrane. The DRir ratio of $\mathrm{PVDF} / \mathrm{PEG} / \mathrm{C}_{3} \mathrm{~N}_{4} /$ Pineapple leaf nanocellulose membrane increased from $12.2 \%$ to 28.4\% compared with that of the pure membrane. The nanoparticles in the PVDF matrix can also improve the crystallinity and thermal stability of the membrane. Moreover, compared with pure PVDF membrane, the prepared composite membrane has stronger mechanical properties, which is of great significance for industrial applications.

\section{Declaration of competing interest}

The authors declare that they have no known competing financial interests or personal relationships that could have appeared to influence the work reported in this paper.

\section{Acknowledgements}

This work was supported by the following: Project funded by China Postdoctoral 
Science Foundation (Grant No. 2020M682884), Natural Science Foundation of

Heilongjiang Province of China (Grant No. LH2021B032) and Heilongjiang Province

Education Department Basal Research Fund (Grant No. 135409416).

\section{References}

[1] A.A. Uliana, N. T.Bui, o. Kamcev, M.K. Taylor, J.J. Urban, J.R. Long, Ion-capture electrodialysis using multifunctional adsorptive membranes, Science 372 (2021) 296-299.

[2] Y. Guo, C. Liu, H. Liu, J. Zhang, H. Li, C. Zhang, Contemporary antibiofouling modifications of reverse osmosis membranes: State-of-the-art insights on mechanisms and strategies, Chemical Engineering Journal 429 (2022) 132400.

[3] C. Liu, C. Wang, Y. Guo, J. Zhang, Y. Cao, H. Liu, Z. Hu, C. Zhang, High-performance polyamide membrane with tailored water channel prepared via bionic neural networks for textile wastewater treatment, J Mater Chem A 7 (2019) 6695-6707.

[4] T.E. Culp, B. Khara, K.P. Brickey, M. Geitner, T.J. Zimudzi, J.D. Wilbur, S.D. Jons, A. Roy, M. Paul, B. Ganapathysubramanian, A.L. Zydney, M. Kumar, E.D. Gomez, Nanoscale control of internal inhomogeneity enhances water transport in desalination membranes, Science 371 (2021) $72-75$.

[5] R. Li, J. Li, L. Rao, H. Lin, L. Shen, Y. Xu, J. Chen, B.-Q. Liao, Inkjet printing of dopamine followed by UV light irradiation to modify mussel-inspired PVDF membrane for efficient oil-water separation, Journal of Membrane Science 619 (2021) 118790.

[6] T.T.V. Tran, S.R. Kumar, S.J. Lue, Separation mechanisms of binary dye mixtures using a PVDF ultrafiltration membrane: Donnan effect and intermolecular interaction, Journal of Membrane Science 575 (2019) 38-49.

[7] H. Liu, X. Liu, F. Zhao, Y. Liu, L. Liu, L. Wang, C. Geng, P. Huang, Preparation of a hydrophilic and antibacterial dual function ultrafiltration membrane with quaternized graphene oxide as a modifier, J Colloid Interface Sci 562 (2020) 182-192.

[8] A. Politano, P. Argurio, G. Di Profio, V. Sanna, A. Cupolillo, S. Chakraborty, H.A. Arafat, E. Curcio, Photothermal Membrane Distillation for Seawater Desalination, Adv Mater 29 (2017).

[9] Z. Guo, Y. Yang, S. Xiang, X. Du, Z. Cui, B. He, H. Wang, J. Li, T. Jiang, Preparation of PVDF membrane based on "In-situ Template-TIPS" technology and the investigation on membrane formation mechanism, microstructure regulation and permeability, Journal of Membrane Science (2020) 118839.

[10] J. Willet, K. Wetser, J. Vreeburg, H.H.M. Rijnaarts, Review of methods to assess sustainability of industrial water use, Water Resources and Industry 21 (2019) 100110.

[11] F. Beygmohammdi, H. Nourizadeh Kazerouni, Y. Jafarzadeh, H. Hazrati, R. Yegani, Preparation and characterization of PVDF/PVP-GO membranes to be used in MBR system, Chemical Engineering Research and Design 154 (2020) 232-240.

[12] Q. Bi, Q. Li, Y. Tian, Y. Lin, X. Wang, Hydrophilic modification of poly(vinylidene fluoride) membrane with poly(vinyl pyrrolidone) via a cross-linking reaction, J Appl Polym Sci 127 (2013) 394-401.

[13] Y.W. Kim, J.K. Choi, J.T. Park, J.H. Kim, Proton conducting poly(vinylidene fluoride-co-chlorotrifluoroethylene) graft copolymer electrolyte membranes, Journal of Membrane Science 313 (2008) 315-322.

[14] Z. Yang, H. Guo, Z.K. Yao, Y. Mei, C.Y. Tang, Hydrophilic Silver Nanoparticles Induce Selective Nanochannels in Thin Film Nanocomposite Polyamide Membranes, Environ Sci Technol 53 (2019) 5301-5308.

[15] M.M. Pendergast, E.M.V. Hoek, A review of water treatment membrane nanotechnologies, Energ Environ Sci 4 (2011) 1946.

[16] Y. Gong, B. Yang, H. Zhang, X. Zhao, A g-C3N4/MIL-101(Fe) heterostructure composite for highly efficient BPA degradation with persulfate under visible light irradiation, J Mater Chem A 6 (2018) 23703-23711.

[17] W. Iqbal, B. Yang, X. Zhao, M. Rauf, I.M.A. Mohamed, J. Zhang, Y. Mao, Facile one-pot 
synthesis of mesoporous g-C3N4 nanosheets with simultaneous iodine doping and $\mathrm{N}$-vacancies for efficient visible-light-driven $\mathrm{H}-2$ evolution performance, Catalysis Science \& Technology 10 (2020) 549-559.

[18] B. Zhou, M. Waqas, B. Yang, K. Xiao, S. Wang, C. Zhu, J. Li, J. Zhang, Convenient one-step fabrication and morphology evolution of thin-shelled honeycomb-like structured g-C3N4 to significantly enhance photocatalytic hydrogen evolution, Appl Surf Sci 506 (2020).

[19] C. Liu, W. Wang, B. Yang, K. Xiao, H. Zhao, Separation, anti-fouling, and chlorine resistance of the polyamide reverse osmosis membrane: From mechanisms to mitigation strategies, Water Res 195 (2021) 116976.

[20] M. Ge, X. Wang, S. Wu, Y. Long, Y. Yang, J. Zhang, Highly antifouling and chlorine resistance polyamide reverse osmosis membranes with g-C3N4 nanosheets as nanofiller, Sep Purif Technol 258 (2021) 117980.

[21] Komal, K. Gupta, V. Kumar, K.B. Tikoo, A. Kaushik, S. Singhal, Encrustation of cadmium sulfide nanoparticles into the matrix of biomass derived silanized cellulose nanofibers for adsorptive detoxification of pesticide and textile waste, Chemical Engineering Journal 385 (2020) 123700.

[22] F. Cheng, Y. Wu, H. Li, T. Yan, X. Wei, G. Wu, J. He, Y. Huang, Biodegradable N, O-carboxymethyl chitosan/oxidized regenerated cellulose composite gauze as a barrier for preventing postoperative adhesion, Carbohydr Polym 207 (2019) 180-190.

[23] J. Lv, G. Zhang, H. Zhang, F. Yang, Graphene oxide-cellulose nanocrystal (GO-CNC) composite functionalized PVDF membrane with improved antifouling performance in MBR: Behavior and mechanism, Chemical Engineering Journal 352 (2018) 765-773.

[24] F. Asempour, D. Emadzadeh, T. Matsuura, B. Kruczek, Synthesis and characterization of novel Cellulose Nanocrystals-based Thin Film Nanocomposite membranes for reverse osmosis applications, Desalination 439 (2018) 179-187.

[25] X. Wang, Y. Zhao, B. Yuan, Z. Wang, X. Li, Y. Ren, Comparison of biofouling mechanisms between cellulose triacetate (CTA) and thin-film composite (TFC) polyamide forward osmosis membranes in osmotic membrane bioreactors, Bioresour Technol 202 (2016) 50-58.

[26] X. Teng, W. Fang, Y. Liang, S. Lin, H. Lin, S. Liu, Z. Wang, Y. Zhu, J. Jin, High-performance polyamide nanofiltration membrane with arch-bridge structure on a highly hydrated cellulose nanofiber support, Science China Materials 63 (2020) 2570-2581.

[27] X. Lu, X. Feng, Y. Yang, J. Jiang, W. Cheng, C. Liu, M. Gopinadhan, C.O. Osuji, J. Ma, M. Elimelech, Tuning the permselectivity of polymeric desalination membranes via control of polymer crystallite size, Nat Commun 10 (2019) 2347.

[28] A. Sabir, M. Shafiq, A. Islam, A. Sarwar, M.R. Dilshad, A. Shafeeq, M.T. Zahid Butt, T. Jamil, Fabrication of tethered carbon nanotubes in cellulose acetate/polyethylene glycol-400 composite membranes for reverse osmosis, Carbohydr Polym 132 (2015) 589-597.

[29] P. Fei, L. Liao, J. Meng, B. Cheng, X. Hu, J. Song, Non-leaching antibacterial cellulose triacetate reverse osmosis membrane via covalent immobilization of quaternary ammonium cations, Carbohydr Polym 181 (2018) 1102-1111.

[30] B. Al-Ghafri, T. Bora, P. Sathe, S. Dobrestov, M. Al-Abri, Photocatalytic microbial removal and degradation of organic contaminants of water using PES fibers, Applied Catalysis B: Environmental 233 (2018) 136-142.

[31] H. Wang, R. Gong, X. Qian, Preparation and Characterization of TiO(2)/g-C(3)N(4)/PVDF Composite Membrane with Enhanced Physical Properties, Membranes (Basel) 8 (2018) 1-9.

[32] L. Zhang, G. Chen, H. Tang, Q. Cheng, S. Wang, Preparation and characterization of composite membranes of polysulfone and microcrystalline cellulose, J Appl Polym Sci 112 (2009) 550-556.

[33] H. Sun, Y. Zhang, H. Sadam, J. Ma, Y. Bai, X. Shen, J.-K. Kim, L. Shao, Novel mussel-inspired zwitterionic hydrophilic polymer to boost membrane water-treatment performance, Journal of Membrane Science 582 (2019) 1-8.

[34] C. Liu, Y. Guo, X. Wei, C. Wang, M. Qu, D.W. Schubert, C. Zhang, An outstanding antichlorine and antibacterial membrane with quaternary ammonium salts of alkenes via in situ polymerization for textile wastewater treatment, Chemical Engineering Journal 384 (2020) 123306.

[35] W. Ma, J. Zhang, X. Wang, S. Wang, Effect of PMMA on crystallization behavior and hydrophilicity of poly(vinylidene fluoride)/poly(methyl methacrylate) blend prepared in 
semi-dilute solutions, Appl Surf Sci 253 (2007) 8377-8388.

[36] S. Cao, N. Zhou, F. Gao, H. Chen, F. Jiang, All-solid-state Z-scheme 3,4-dihydroxybenzaldehyde-functionalized $\mathrm{Ga} 2 \mathrm{O} 3$ /graphitic carbon nitride photocatalyst with aromatic rings as electron mediators for visible-light photocatalytic nitrogen fixation, Applied Catalysis B: Environmental 218 (2017) 600-610.

[37] C. Liu, Y. Liu, Y. Guo, C. Wang, Z. Hu, C. Zhang, High-hydrophilic and salt rejecting PA-g/co-PVP RO membrane via bionic sand-fixing grass for pharmaceutical wastewater treatment, Chemical Engineering Journal 357 (2019) 269-279.

[38] Y. Guo, C. Liu, H. Liu, W. Wang, H. Li, C. Zhang, Influences of gamma-ray irradiation on PVDF membrane behavior: An experimental study based on simulation and numerical analysis, Polymer Degradation and Stability 193 (2021) 109722.

[39] S. Rajabzadeh, C. Liang, Y. Ohmukai, T. Maruyama, H. Matsuyama, Effect of additives on the morphology and properties of poly(vinylidene fluoride) blend hollow fiber membrane prepared by the thermally induced phase separation method, Journal of Membrane Science 423-424 (2012) 189-194.

[40] J. Zhao, L. Shi, C.H. Loh, R. Wang, Preparation of PVDF/PTFE hollow fiber membranes for direct contact membrane distillation via thermally induced phase separation method, Desalination 430 (2018) 86-97.

[41] J. Zhao, J.Y. Chong, L. Shi, R. Wang, PTFE-assisted immobilization of Pluronic F127 in PVDF hollow fiber membranes with enhanced hydrophilicity through nonsolvent-thermally induced phase separation method, Journal of Membrane Science (2020) 118914.

[42] Y. Guo, C. Liu, W. Xu, G. Liu, K. Xiao, H.-Z. Zhao, Interpenetrating network nanoarchitectonics of antifouling poly(vinylidene fluoride) membranes for oil-water separation, Rsc Adv 11 (2021) 31865-31876.

[43] D. Hou, J. Wang, X. Sun, Z. Ji, Z. Luan, Preparation and properties of PVDF composite hollow fiber membranes for desalination through direct contact membrane distillation, Journal of Membrane Science 405-406 (2012) 185-200. 